\title{
Mordida aberta anterior em dentição mista - relato de caso
}

\section{Anterior open bite in mixed dentition - case report}

\author{
Gisele Fernandes Dias \\ Universidade Estadual de Ponta Grossa - UEPG - Ponta Grossa - Brasil \\ Centro Universitário de União da Vitória - UNIUV - União da Vitória - Brasil \\ giodonto@hotmail.com \\ Pamela Thais Gomes do Valle \\ Centro Universitário de União da Vitória - UNIUV - União da Vitória - Brasil \\ pamelatais97@hotmail.com \\ Fernanda Roiek Bojarski \\ Centro Universitário de União da Vitória - UNIUV - União da Vitória - Brasil \\ fernandabojarski@outlook.com \\ Fabiana Bucholdz Teixeira Alves \\ Universidade Estadual de Ponta Grossa - UEPG - Ponta Grossa - Brasil \\ fabi.teixeira@uol.com.br
}

\section{Resumo}

A mordida aberta anterior (MAA) é considerada uma má oclusão caracterizada pela falta de contato entre os dentes anteriores, superiores e inferiores. O objetivo deste trabalho é relatar e discutir com base na literatura os fatores etiológicos relacionados à MAA, diagnóstico e tratamento interceptador ortodôntico precoce em crianças. A intervenção precoce foi realizada em uma paciente do sexo feminino, com cinco anos de idade, com diagnóstico de MAA. Foram realizados exames intrabucais, extra bucais, odontogramas e índice de placa. Procedimentos como bandagem, moldagem, confecção do aparelho do tipo grade lingual e cimentação. Os acompanhamentos foram realizados por meio de consultas clínicas mensais e acompanhamento fotográfico. $O$ aparelho do tipo grade lingual foi utilizado por seis meses, com redução de medidas de um milímetro de overjet e overbite. $\mathrm{O}$ tratamento realizado teve o intuito de restabelecer a função e a estética, oferendo melhoria em relação a auto estima da criança.

Palavras-chave: MAA, etiologia, diagnóstico, tratamento, qualidade de vida.

\section{Abstract}

The anterior open bite (MAA) is considered a malocclusion characterized by a lack of contact between the upper and lower anterior teeth. The objective of this work is to report and discuss, based on the literature, the etiological factors related to MAA, diagnosis and early orthodontic interceptor treatment in children. Early intervention was performed in a 5-year-old female patient with a diagnosis of AMA. Intraoral, extra buccal, odontograms and plaque index were performed. Procedures such as banding, molding, confection of the lingual grille type and cementation. The follow- 
ups were performed through monthly clinical consultations and photographic followup. The lingual grille was used for six months, with a reduction of $1 \mathrm{~mm}$ of overjet and overbite measurements. The aim of the treatment was to restore function and aesthetics, offering improvement in relation to the child's self-esteem.

Keywords: MAA, etiology, diagnosis, treatment, quality of life.

\section{Introdução}

A mordida aberta anterior (MAA) pode ser definida como o aumento do tamanho vertical entre as arcadas dentárias na região anterior. A discrepância gerada na oclusão evita o encaixe harmônico entre os dentes superiores e inferiores, resultando em consequências tanto funcionais quando estéticas na criança quando presente na dentição decídua (MOROSINI et al., 2011).

Alterações funcionais podem ocorrer na presença de hábitos nocivos, sendo que as heranças genéticas e a ossificação contribuem para o desenvolvimento e exacerbação da MAA (GRANVILLE-GARCIA et al., 2008). O prognóstico positivo é dependente da interversão ortodôntica precoce e se causada por hábitos nocivos, os mesmos devem ser reeducados para que se estabeleça a oclusão esperada (MACHO et al., 2012).

A relação entre os hábitos orais e a influência do aleitamento têm repercutido na má-oclusão (MIOTTO et al., 2014). Romero (2011) avaliou a relação da amamentação materna exclusiva com a MAA, verificou-se que crianças que nunca foram amamentadas ou foram por menos de 1 mês apresentariam 7,1 vezes a mais de chance do que as que receberam amamentação por mais de 12 meses. Já as que foram amamentadas por um período maior que 12 meses ocorreria 3,7 vezes menos chance de apresentar MAA. Foi ainda avaliado, também nesses mesmos grupos, em relação aos hábitos não-nutritivos, em que $81,5 \%$ apresentariam tais hábitos pertencentes ao grupo que não receberam amamentação materna exclusiva. Ou seja, quanto maior for o tempo que a criança for amamentada, menores possibilidades de praticarem hábitos de sucção nãonutritivos. Foi constatado também que a cada ano de insistência nos hábitos de sucção não nutritiva aumentaria 2,38 vezes o risco de apresentarem MAA.

A amamentação exclusiva é necessária para o correto crescimento e desenvolvimento das estruturas do sistema estomatognatico, com a finalidade de diminuir a prevalência da má-oclusão (MOIMAZ et al., 2013). A intervenção precoce da MAA, proporciona o crescimento dento-ósseo em harmonia facial (MOROSINI et al., 2011), pois evita a modificação dento-alveolar que promova alterações esqueléticas danosas.

Portanto, o objetivo do trabalho relatar e discutir com base na literatura os fatores etiológicos relacionados à MAA, diagnóstico e tratamento interceptador ortodôntico precoce em portadores de MAA relacionada à etiologia, diagnóstico e tratamento clínico.

\section{Descrição do caso clínico e metodologia de trabalho}

Paciente A.R.C., sexo feminino, com 5 anos de idade, apresentou-se na cliníca de odontopediatria no Centro universitário de União da Vitoria (UNIUV), acompanhada da responsável, em março de 2018.

Ao exame clinico intrabucal inicial apresentou ausência de lesões cariosas, fratura na incisal em esmalte do dente 51, dentes 41, 31, 16 e 26 em erupção, portadora de má oclusão do tipo MAA (Figura 1), padrão de crescimento tipo II, de 
caráter hereditário. As características clínicas apresentadas diagnosticaram: interposição de lábio inferior, língua com deglutição atípica, ausência de alteração fonética, normalidade de articulação têmporo-mandibular (ATM), padrão respiratório misto bucal e nasal, ausência de tonsilas palatinas, padrão de musculatura peribucal hipotônico, o freio labial superior, inferior e lingual de inserção normal, palato profundo ogival, e classificado como má-oclusão esquelética do tipo MAA. A história clínica da paciente foi declarada pelos responsáveis, que informaram a presença de amamentação exclusiva até dois meses de idade. A presença de hábitos de sucção não-nutritiva de chupeta e a mamadeira persistentes até os 3 anos de idade. Atualmente paciente apresenta hábitos de onicofagia e permanência da boca aberta durante o sono. Na avalição periodontal foi verificado a presença de biofilme visível, tanto na região anterior como na posterior e interdental, entretanto sem presença de inflamação evidente. Com resultado de $65 \%$ no índice de placa, ou seja, existe risco de propensão a atividade cariogênica. Na avaliação extraoral; ausência de simetria facial (Figura 2), de perfil convexo (Figura 3). E outras características intrabucais como; espaço visível apenas entre incisivos centras superiores, forma do arco superior ogival. Segundo relato familiar, a criança sofreu traumatismo dentário 51 do tipo fratura incisal, com ausência de cuidados pós-trauma.

Foi proposto o tratamento ortodôntico interceptativo, com indicação do aparelho do tipo grade palatina fixa, com avaliações clínicas mensais, de acompanhamento clínico e fotográfico no período de 6 meses. A grade palatina foi utilizada durante o período de 6 meses, em que foi esclarecido aos responsáveis a limitação do tratamento e a necessidade de continuidade devido ao padrão esquelético de Classe II (Figura 4).

Durante o acompanhamento clínico ocorreu a troca de dentição infantil precoce motivado por trauma dental anterior, com sucessão do dente $11 \mathrm{com}$ hipoplasia focal, (Figura 5).

Em outubro de 2018, foi removido o aparelho e realizado o acompanhamento clínico do paciente e desenvolvimento da dentição, em intervalos trimestrais no primeiro semestre de 2019. No momento da finalização foi diagnosticado a diminuição das medidas de overjet e overbite, em ambas as arcadas. Entretanto, devido ao padrão de crescimento facial, a paciente encontrase em acompanhamento clínico na clínica de graduação da faculdade (Figura 7)

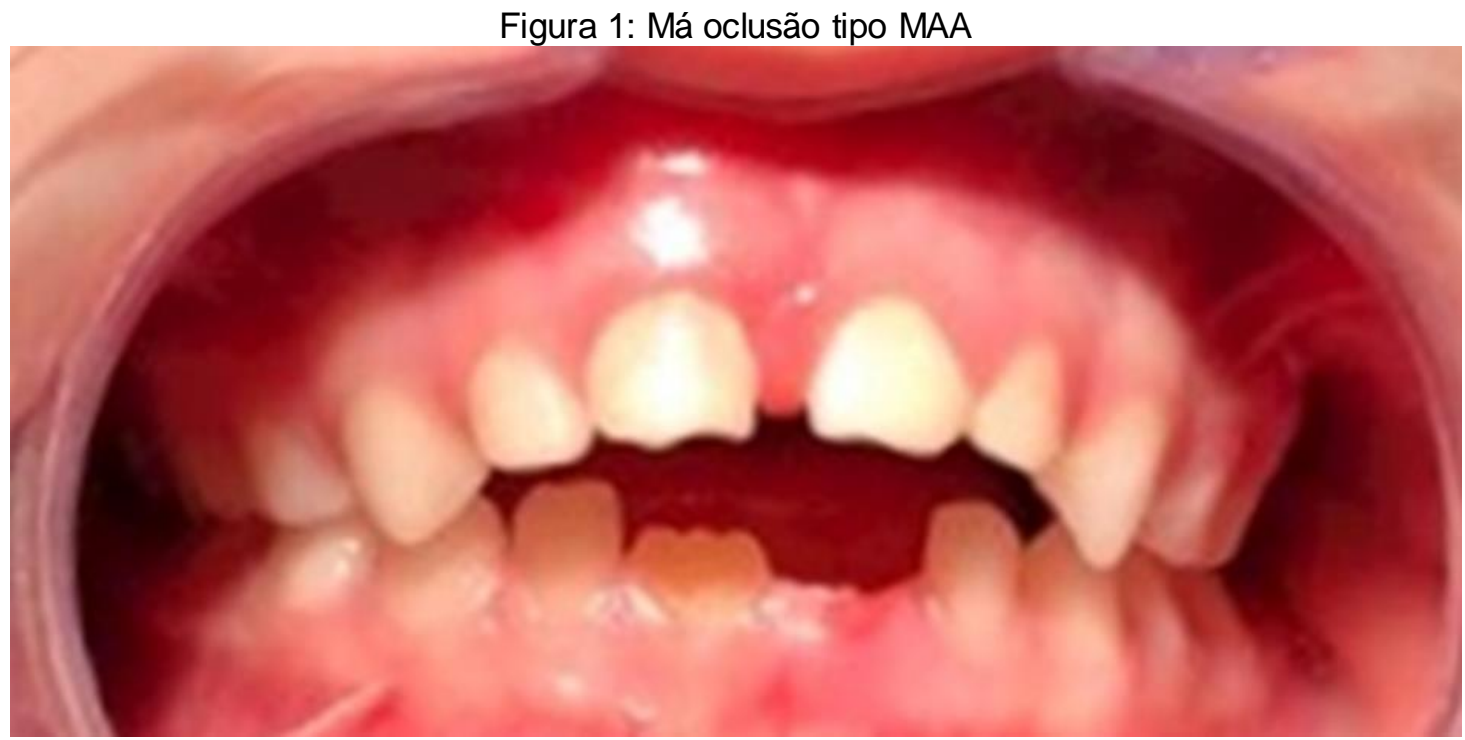

Fonte: Autoria própria (2018)

Figura 2: Foto frontal (ausência de simentria facial) 


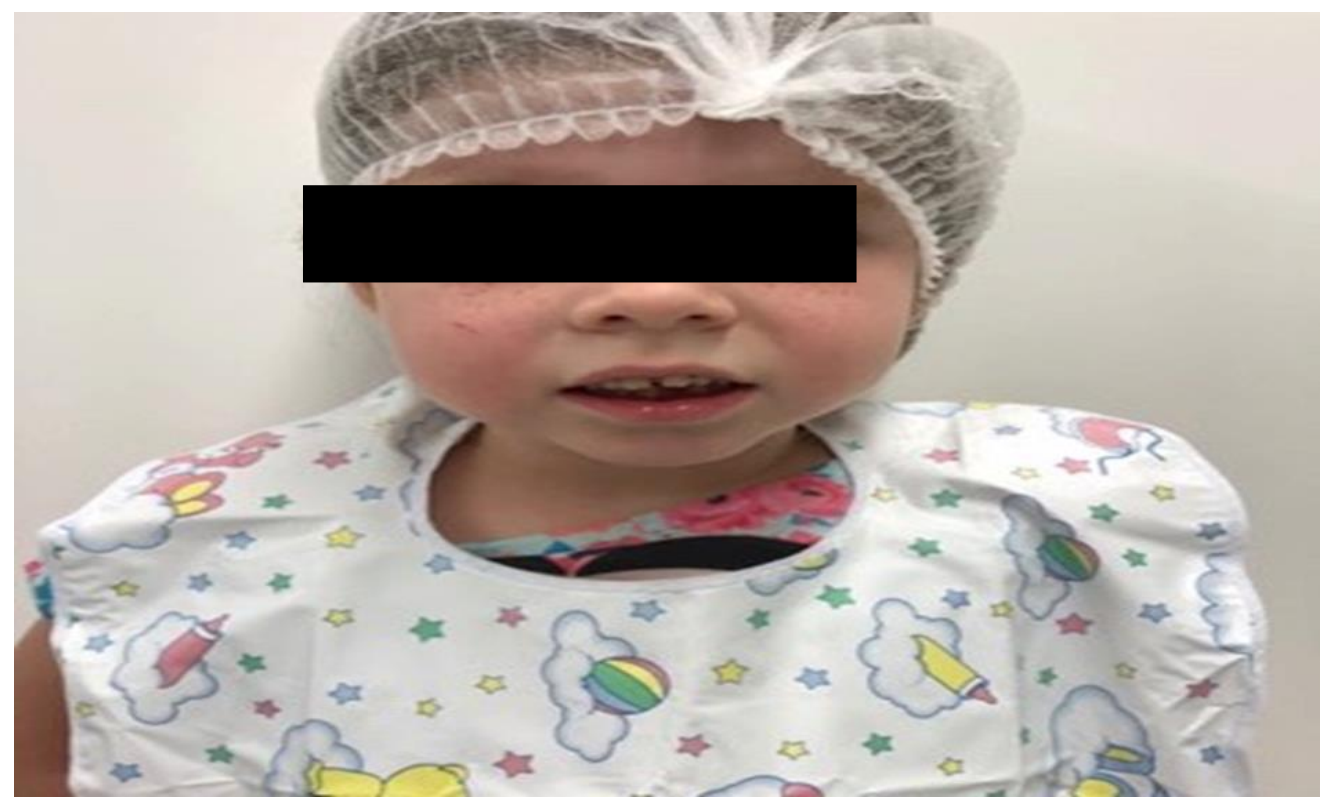

Fonte: Autoria própria (2018)

Figura 3: Foto lateral (perfil convexo)

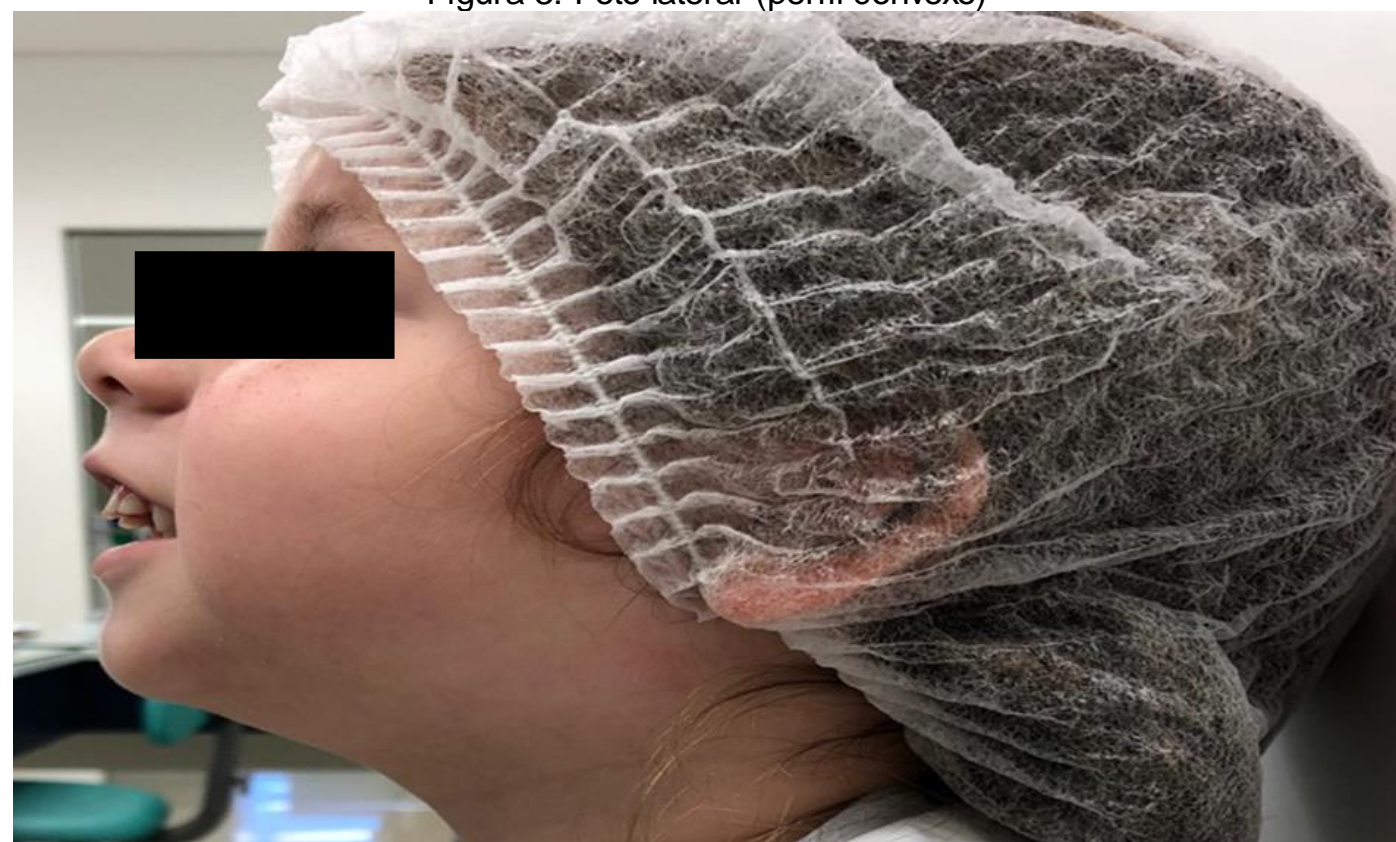

Fonte: Autoria própria (2018)

Figura 4: Cimentação da grade palatina (abril 2018)

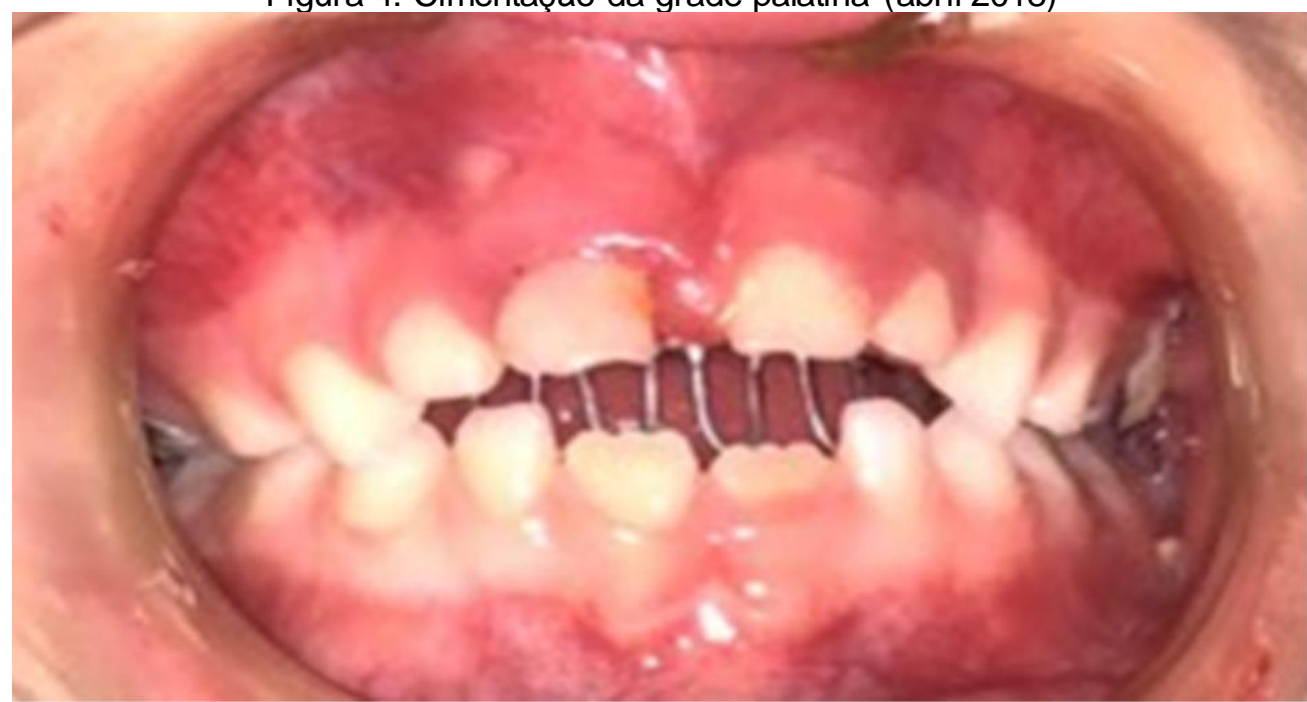


Fonte: Autoria própria (2018)

Figura 5: Manutenção do aparelho grade palatina (julho 2018)

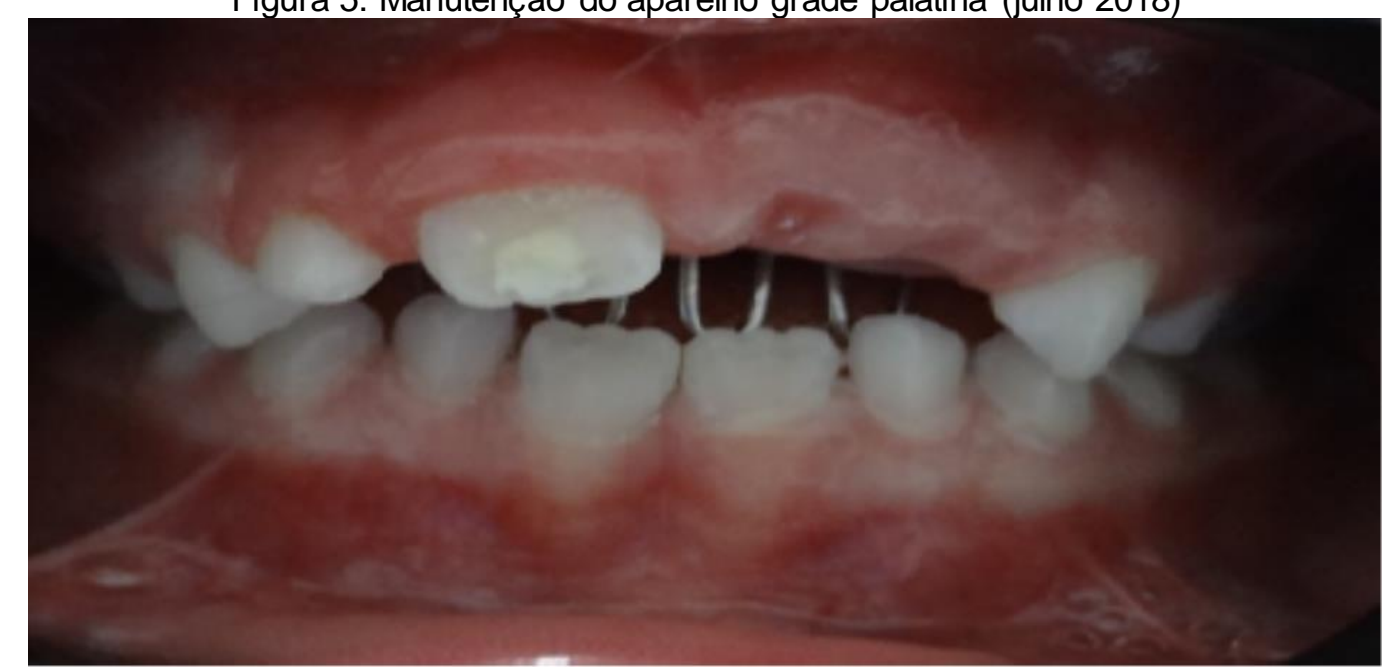

Fonte: Autoria própria (2018)

Figura 6: Remoção da grade palatina (outubro 2018)

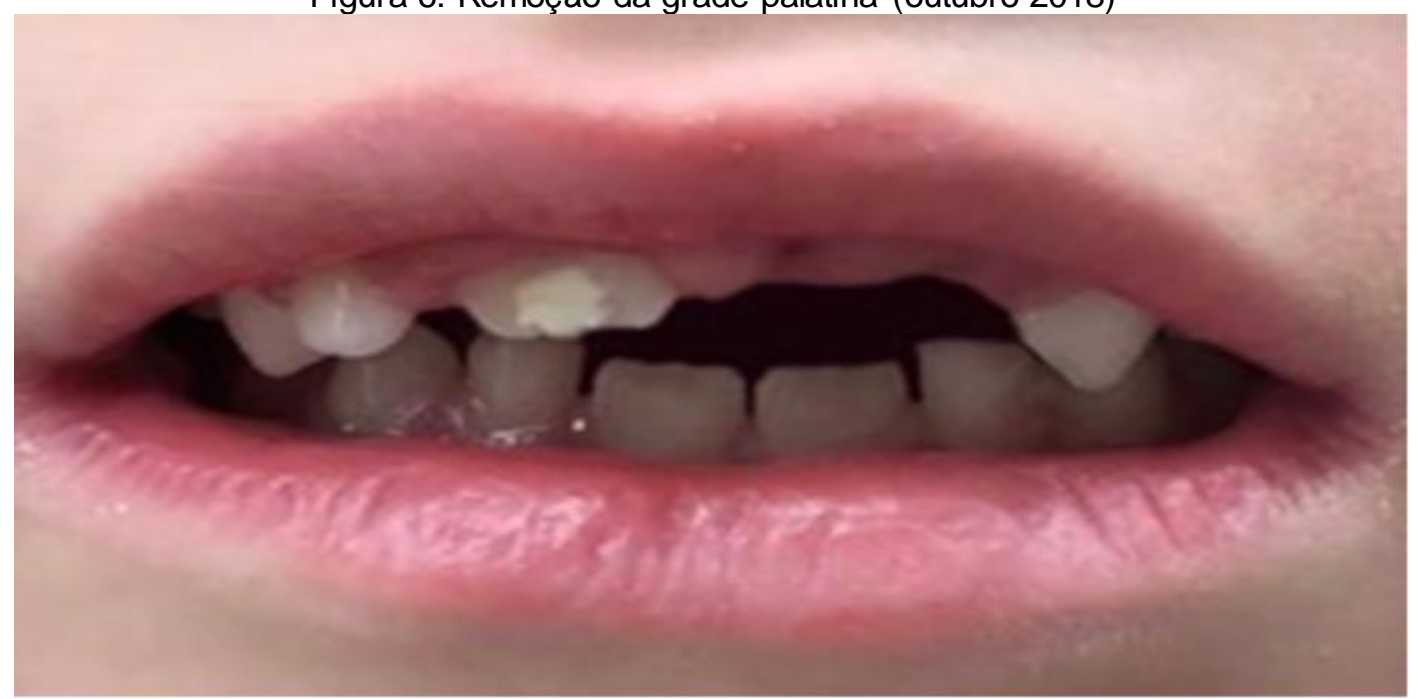

Fonte: Autoria própria (2018)

Figura 7: Foto atual (abril 2019) 


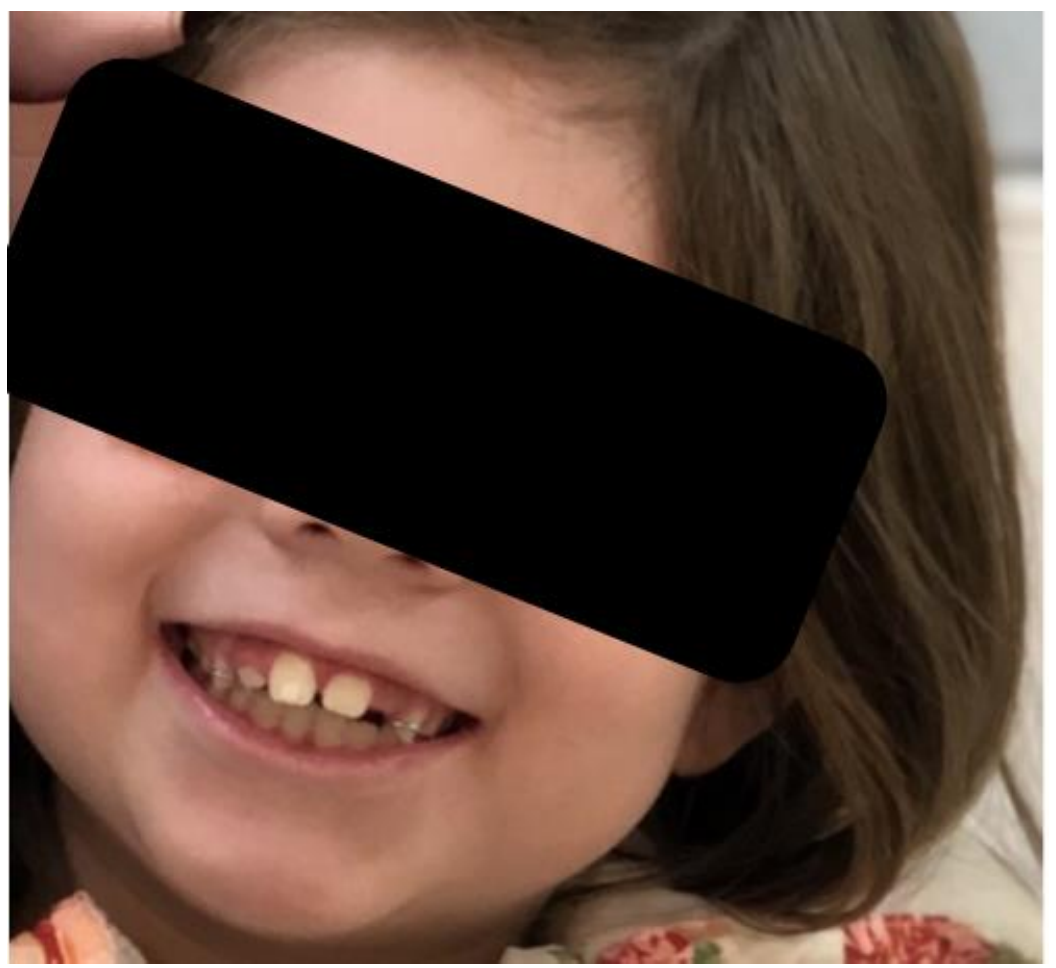

Fonte: Autoria própria (2019) seção sequente.

Encerrada a apresentação do caso clínico, os dados serão discutidos na

\section{Discussão}

A MAA pode ser causada por condição esquelética, genetica ou por fatores ambientais (TANNY et al., 2018). Como resultado de etiologias distintas, na marioria das vezes apresentadas como hábitos de sucção e influência genética. Foi feito um estudo monstrando a influência do polimorfismo genético na proteína MMP9 que está fortemente associada com MAA (KUCHLER et al., 2017). Os resultados mostraram que fatores genéticos estão envolvidos com a etiologia MAA, ou se presente, o fator protetor genótipo GG, a criança mesmo apresentando hábitos deletérios estária protegida da MAA (KUCHLER et al., 2017). Para Antoun et al. (2018) os genes dominam o padrão de crescimento, por meio da herança genética. Portanto, quando ocorre a instalação da MAA não significa que ela ocorreu apenas com a presença hábito (FIALHO et al., 2014). Em relação ao caso clínico em discussão, a paciente apresentava herança genética e hábitos de sucção labial.

Com base em um estudo transversal feito por Pereira (2017), com o objetivo de avaliar a associação dos hábitos deletérios com as estruturas estomatognáticas, em uma amostra de 289 crianças, concluíram que as persistências de hábitos deletérios podem modificar as estruturas e a funções na respiração, fala e na oclusão. Durante a fase de crescimento e desenvolvimento facial, os hábitos deletérios causam desarmonia na musculatura, comprometendo não só o desenvolvimento da oclusão dentária, mas também o sistema estomatognático (VALCHIA et al., 2017). A criança que não recebe amamentação exclusiva, apresenta grandes chances de desenvolver MAA com repercussões na oclusão, pois utilizará de outros meios, como hábitos de sucção não-nutritivos, potencialmente prejudiciais, para se sentir satisfeito em suas necessidades de sucção (CHEN et al., 2016). Porém, a ocorrência da MAA, pode acometer também 
crianças amamentadas na forma natural e correta devido às etiologias multifatoriais (DOGRAMACl et al., 2017).

Com o diagnóstico precoce, e com a intervenção mesmo em dentição mista é possível corrigir a má oclusão evitando maiores desarmonias dento esqueléticas, estéticas e faciais na dentição permanente (DIAS et al., 2019). Um estudo realizado por meio de casos clínicos de MAA em dentição mista, com a interceptação da grade palatina fixa, obteve o diagnóstico através de hábitos de sucção deletérios apresentados em 5 crianças. $O$ aparelho foi usado por 6 a 7 meses, e os resultados foram excelentes, pois houve a correção da má oclusão, restaurando o equilíbrio e a harmonia das estruturas dento esqueléticas (LIRA et al., 2018). Para Araiza et al. (2017) a classe II esquelética apresenta maior complexidade no tratamento, pois não tem à tendência de correção precoce, sendo cada vez mais agravada e intensificada com o passar da idade. Relacionando ao caso clínico, embora tenha ocorrido a intervenção precoce, a redução da medida de overjet ainda não houve resultado significativo. A interposição labial causa vestibularização dos incisivos superiores e os incisivos inferiores tornam-se lingualizados, a falta de posição correta dos lábios afeta com maior gravidade a protrusão maxilar (FUKUMITSU et al., 2003). A sucção eleva a força do lábio contra os dentes, permitindo pressão negativa intraoral, alterando a morfologia orofacial, impedindo que os incisivos alcancem contato oclusal e não atinja o correto selamento labial (ARTESE et al., 2011; SACCOMANNO et al., 2012; WERTSÉN et al., 2017).

Quando a criança apresenta um modelo de crescimento desfavorável e prevalência vertical, também poderá levar à má oclusão de MAA, ou até propiciá-la. Se diagnosticada e classificada como mordida aberta esquelética, o fator etiológico responsável seria o crescimento desfavorável, relacionado à discrepância entre as bases ósseas e ausência de contatos dentários anteriores (ANTOUN et al., 2018). Em relação ao caso clínico, a paciente possui classificação esquelética e tendência de crescimento classe II. A má oclusão torna o individuo com maior vulnerabilidade física afetando também o estado psicológico, consequentemente trazendo incapacidade social (MACHADO et al., 2014; DIMBERG et al., 2015; SUN et al., 2017; MARTINS et al., 2019). O tratamento interceptativo precoce diminui o impacto psicossocial, ao promover bem-estar social e emocional, com repercussões na qualidade de vida das crianças (PIASSI et al., 2016). Reconhecendo as etiologias envolvidas, interceptando-as, oferecendo tratamento adequado e contenção, pode-se reduzir a recidiva, apesar do tratamento desafiador devido à complexidade (ASIRY et al., 2015; LITTLEWOOD, 2016). O objetivo é recuperar a estética facial, ao restaurar a oclusão ideal ainda em dentição mista, para que na permanente evite intervenções mais severas (VALENCIA et al., 2014; MANJARRÉS et al., 2015). Para Rosa et al. (2019), a correção da MAA ativa em dentição mista não é o principal objetivo, e sim a eliminação dos hábitos para funcionais, uma vez que a correção durante a fase pré puberal tem um aumento de desenvolvimento significativo.

\section{Conclusão}

O objetivo deste trabalho foi relatar e discutir com base na literatura os fatores etiológicos relacionados à MAA, diagnóstico e tratamento interceptador ortodôntico precoce em crianças.

A avaliação clínica precoce dos fatores etiológicos da MAA, promove a intervenção em hábitos deletérios responsáveis pela alteração da estrutura 
orofacial. Estudos revelam que a MAA é um grave problema de oclusão que pode afetar a qualidade de vida dos portadores. O tratamento da MAA é desafiador.

Ao se avaliar cada situação específica e etiologia envolvida, constituem determinantes do sucesso do tratamento em equipe multidisciplinar. $O$ diagnóstico das más oclusões verticais deve ser feito no contexto das estruturas dentárias e esqueléticas, por meio da correta identificação dos fatores etiológicos das más oclusões verticais. Destarte, impede-se transtornos posteriores que possam afetar a qualidade de vida infantil.

No caso clínico discutido, embora os resultados sejam mínimos em valores de overjet e overbite, a possiblidade de intervenção precoce e novas intervenções ortodônticas em andamento permitem o acompanhamento longitudinal da paciente e promoção da qualidade de vida da criança.

\section{Referências}

ANTOUN, T. R. A.; et al. Mordida aberta anterior- uma revisão de literatura. Rev. Odontol. Univ. São Paulo, v. 30, n. 2, p. 190-199, 2018.

ARAIZA, C. D. J.; MONDRAGÓN, B. T. D. Tratamiento ortopédico SN6 en adolescente con maloclusión clase II: reporte de caso / Orthopedic treatment SN6 in an adolescentwith class II malocclusion. case report. Asociación Dental Mexicana. v. 74, n. 3 p. 152-158, 2017.

ARTESE, A.; et al. Critérios para o diagnóstico e tratamento estável da mordida aberta anterior. Dental Press J Orthod. v. 16, n. 3, p. 136-61, 2011.

ASIRY, M. Anterior open bite treated with myofunctional therapy and palatal crib. The jornal of contemporany dental pratice. v. 16, n. 3, p. 243-247, 2015.

BOB, R. K. et al. Tratamento da mordida aberta anterior com o uso de grade palatina: relato de caso. Revista UNINGÁ Review. v. 20, n. 1, jan. 2018.

CHEN, X.; et al. Effects of breast-feeding duration, bottle-feeding duration and oral habits on the occlusal characteristics of primary dentition. Journal of Peking University Health sciences. v. 15, n. 46, 2016.

DIAS, F. A.; et al. Stability of early treatment of anterior open bite: clinical performance of bonded lingual spurs. Dental Press J Orthod. v. 46, n. 1, p. 68-73, 2019.

DIMBERG, L.; AMRUP, K.; BOMDEMARK, L. The impact of malocclusion on the quality of life among children and adolescents: a systematic review of quantitative studies. European Journal of Orthodontic. V. 37, n. 3, p. 238-47, 2015.

DOGRAMACI, E. J.; RISSI-FEDELE, G.; DREYER, C. W. Malocclusions in young children: Does breast-feeding really reduce the risk? A systematic review and metaanalysis. The Journal of the American Dental Association, ed. 6, v. 148, n. 8, p. 566-574, 2017.

DÓNORIO, L. Oral dysfunction as a cause of malocclusion. Orthodontics \& craniofacial research. v. 22, n. 1, p. 43-48, 2019. 
FIALHO, M. P. N.; et al. Relação entre morfologia facial, mordida aberta anterior e hábitos de sucção não nutritivos durante a fase de dentição decídua. Dental Press J Orthod. v. 19, n. 3, p. 108-113, 2014.

FUKUMITSU, K.; OHNO, F.; OHNO, T. Lip sucking and lip biting in the primary dentition: two cases treated with a morphological approach combined with lip exercises and habituation. International Journal Orofacial Myology. v. 29, p. 4257, 2003.

GRANVILLE-GARCIA, A. F.; FERREIRA, J. M. S.; MENEZES, E. A. Prevalência de mordida aberta anterior e protrusão dentária em pré-escolares da cidade do Recife (PE, Brasil). Ciênc. saúde colet., Rio de janeiro. v. 15, n. 2, p. 3265-3270, 2008.

GRINFREDE, T. F. Deleterious oral habits and its consequences in Pediatric Dentistry. Rev. bras. odontol., Rio de Janeiro, v. 73, n. 2, p. 144-9, abr./jun. 2016.

KUCHLER, E. C.; et al. Genetic Polymorphism in MMP9 May Be Associated with Anterior Open Bite in Children. Braz. Dent. J. Ribeirao Preto, v. 28, n.3, p.277-280, 2017.

LIRA, A. L. S.; SILVA, C. R. Aparelho ortodôntico fixo com grade palatina para correção da mordida aberta anterior relato de casos / Fixed orthodontic appliance with palatine crib for anterior open bite correction case reports. Orthodontics science and practice. v. 11, n. 42, p. 94-100, 2018.

LITTENCOURT, F. J.; et al. Retaining corrected skeletal open bites. How can we increase the stability of our results? L'Orthodontie Française. v. 87, n. 4, p. 457465, 2016.

LITTLEWOOD, S. J. Retaining corrected skeletal open bites. How can we increase the stability of our results? L'Orthodontie Française. v. 87 n. 4, p. 457-465, 2016.

$\mathrm{MACHO}, \mathrm{V}$. Prevalência de hábitos orais deletérios e de anomalias oclusais numa população dos 3 aos 13 anos. Revista Portuguesa de Estomatologia, Medicina Dentária e Cirurgia Maxilofacial. v. 53, n. 3, p. 143-147, 2012.

MACHADO, D. B.; et al. Factors associated with the prevalence of anterior open bite among preschool children: A population-based study in Brazil. Dental Press J. Orthod. Maringá, v. 19, n.15, p. 103-109, 2014.

MANJARRÉS, R. C. C.; TELLO, M. R. P. Manejo temprano de la maloclusión clase II división 2. Revisión de la literatura. Rev. estomatol. v. 23, n. 1, p. 57-63, 2015.

MARTINS, L. P.; et al. Má oclusão e vulnerabilidade social: estudo representativo de adolescentes de Belo Horizonte, Brasil. Dental Press J. Orthod. Maringá, v. 24, n. 2, p. 393-400, 2019.

MIOTTO, M. H.; et al. Prevalência de mordida aberta anterior associada a hábitos orais deletérios em crianças de 3 a 5 anos de Vitoria, ES. Revista CEFAC, v. 16, n. 4, p. 1303-1310, 2014. 
MOIMAZ, S. A.; et al. E e ect of breastfeeding in the acquisition of non-nutritive sucking habits and malocclusion prevention. Rev Odontol UNESP. v. 42, n. 1, p. 31-36, 2013.

MOROSINI, I. A.;et al. Mordida aberta anterior: A influência dos hábitos deletérios no crescimento facial e na oclusão dentária - Relato de caso clínico. Orthodontic Science and Practice. v. 4, n. 15, p. 683, 2011.

OLIVEIRA, J. M. L.; et al. Etiology and treatment of anterior open bite. Journal Health Sci Inst. v. 29, n. 2, p. 92-5, 2011.

PEREIRA, T. S. Associação entre hábitos orais deletérios e as estruturas e funções do sistema estomatognático: percepção dos responsáveis. CoDAS, São Paulo, p. 65, 2017.

PIASSI, E.; ANTUNES, L. S.; ANTUNES, L. A. A. Orthodontic treatment reduces the impact on children and adolescents' oral health-related quality of life. Indian $\mathbf{J}$ Dent Res. v. 27, n. 2, p. 213-9, 2016.

ROMERO, C. C.; et al. Breastfeeding and non-nutritive sucking patterns related to the prevalence of anterior open bite in primary dentition. Journal. Appl. Oral Sci., Bauru, v. 19, n. 2, p. 161-168, 2011.

ROSA, M.; QUINZI, V.; MARZO, G. et al. Paediatric Orthodontics Part 1: Anterior open bite in the mixed dentition. European Journal of Paediatric Dentistry. V. 20, n. 1, p. 80-82, 2019.

SACCOMANNO, S.; et al. Causal relationship between malocclusion and oral muscles dysfunction: a model of approach. European J Paediatr Dent. v. 13, n. 4, p. 321-3, 2012.

SUN, L.; et al. Relationship Between the Severity of Malocclusion and Oral Health Related Quality of Life: A Systematic Review and Meta-analysis. Oral Health and Preventive Dentistry. v.15, n. 6, p. 503-517, 2017.

TANNY, L.; et al. Non-orthodontic intervention and non-nutritive sucking behaviours: A literature review. Journal of Medical Sciences. v. 34, p. 215-222, 2018.

VALCHIA, G. G. C.; et al. Mordida aberta anterior e hábitos bucais deletérios em crianças pré- escolares de escola pública. Rev. Bras. Odontol.v. 74, n. 4, p. 268, 2017.

VALENCIA, A. M.; HURTADO, A. M.; HERNÁNDEZ, J. A. Tratamiento temprano de la mordida abierta anterior con aparatología ortopédica funcional. Reporte de caso. Rev. estomatol. v.22, n. 2, p. 20-26, 2014.

WERTSÉN, M. STENBERG, M. Measuring lip force by oral screens Part 2: The importance of screen design, instruction and suction. Clin Exp Dent Res. v. 3, n. 5, p. 191-197, 2017. 